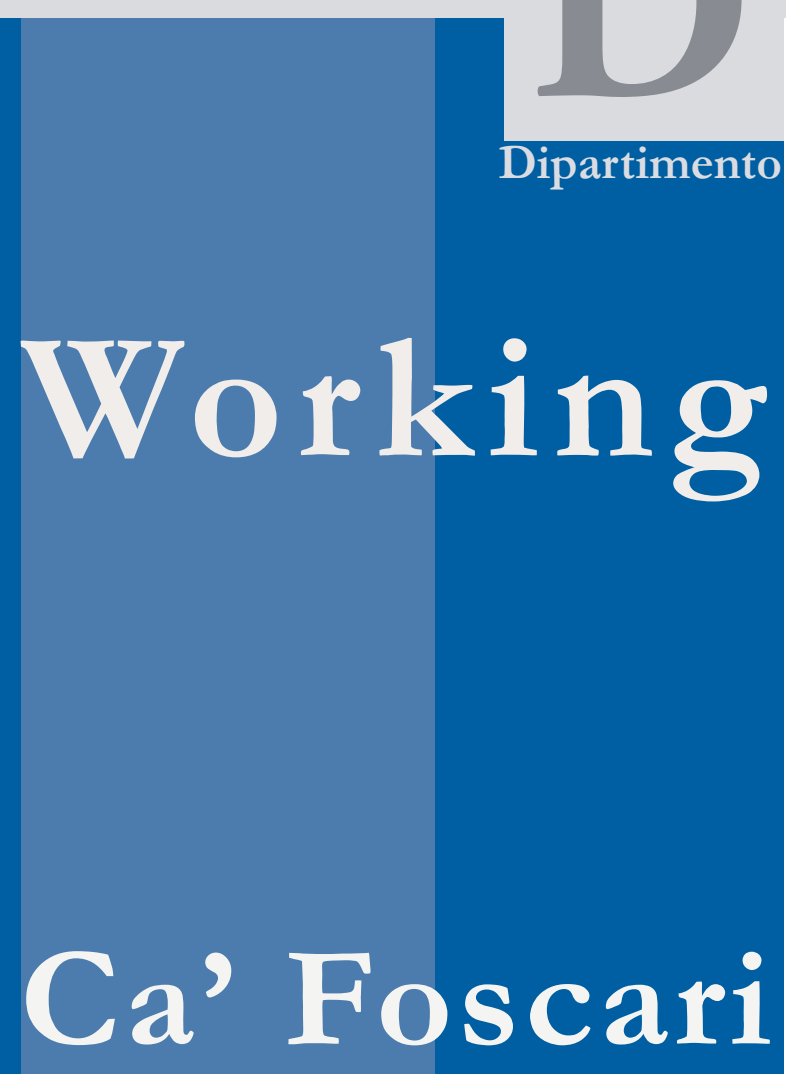

Paper

Department

of Economics

University of

Venice

Marco Giansoldati

International Fragmentation and Agglomeration: From Theory to Empirics 


\title{
International Fragmentation and Agglomeration: From Theory to Empirics
}

\author{
Marco Giansoldati \\ Ca' Foscari University of Venice
}

First Draft: March 2010

\begin{abstract}
This paper deals with fragmentation both theoretically and empirically. Not only it presents a picture of the existing literature on the field but it also provides some basic hints for future investigation. It pays particular attention to the possible theoretical dichotomy between fragmentation and agglomeration, whilst supplying empirical evidence in support of their coexistence. Moreover, the paper focuses on the linkages between fragmentation and trade, with an emphasis on vertical intra-industry trade in intermediates. Eventually, the contribution stresses that much more attention should be paid on how fragmentation shapes the role of industrial districts within the international organisation of production. Further investigation from different strands of literature (GVCs and GPNs) is needed to shed some light on the role of local production systems in the global architecture of manufactures.
\end{abstract}

\section{Keywords}

Fragmentation, agglomeration, intra-industry trade, Global Value Chains, Global Production Networks

\section{JEL Codes}

F11, F12, F20, F32

\author{
Address for correspondence: \\ Marco Giansoldati \\ Department of Economics \\ Ca' Foscari University of Venice \\ Cannaregio 873, Fondamenta S.Giobbe \\ 30121 Venezia - Italy \\ marco.giansoldati@unive.it
}

This Working Paper is published under the auspices of the Department of Economics of the Ca' Foscari University of Venice. Opinions expressed herein are those of the authors and not those of the Department. The Working Paper series is designed to divulge preliminary or incomplete work, circulated to favour discussion and comments. Citation of this paper should consider its provisional character.

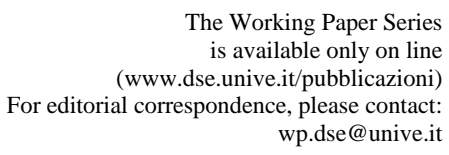

The Working Paper Series
Department of Economics

Ca' Foscari University of Venice

Cannaregio 873, Fondamenta San Giobbe

30121 Venice Italy

Fax: ++390412349210 


\section{Introduction}

In the early '90s, Jones and Kierzkowski (1990 [17]) introduced a new concept, known as "fragmentation", to study the dynamics of the international organisation of production. This approach considers the growth of a firm limited by the rise of marginal costs. To prevent from a slow expansion, and eventually a halt to the growth of a firm, the manufacturing process would then be subdivided into vertically integrated blocks, linked through service activities, such as logistics, communication, etc. In times of low transport costs and fewer institutional barriers, each production block could be located domestically or overseas according to a variety of reasons, i.e. cheap factors of production, market vicinity, oligopolistic behaviours, public incentives or disincentives, etc. In developing each of these arguments, a new perspective emerged, allowing for a better understanding of both the international organization of production between and within firms (Ethier, 1986 [13]; Markusen, 1995 [29], 1988 [28], Markusen and Maskus, 2002 [30]; Markusen and Venables, 2000 [32], 1998 [31]) and the rise of trade and international networks of SMEs.

The term 'fragmentation' came up indeed after several attempts of definition. For example, Feenstra (1998 [14]), introduced the term "disintegration" of the production process across different countries. Bhagwati and Dehejia (1994 [10]) mentioned this phenomenon as a "kaleidoscope comparative advantage"; Krugman (1996 [26]) used the phrase "slicing the value chain", whereas Leamer (1996 [27]) preferred "delocalisation" and Antweiler and Trefler (1997 [5]) "intra-mediate trade". Arndt (1997 [6]) spoke of "intra-product specialisation"; whereas Dixit and Grossman (1982 [12]) wrote on "multistage production"; finally Hummels, Rapoport and Yi (1997 [16]) introduced the term of "vertical specialisation".

All these attempts were not of a semantic nature, but rather derived from being fragmentation a very complex phenomenon. In fact, fragmentation can both derive from a subdivision of an integrated production process of a large MNE and/or from a decision of a number of SMEs to integrate and coordinate their pieces of production on a larger scale. In this latter case scholars tend also to use the term "networking", and usually refer to a mix of cooperation and competition to explain why firms coordinate across their proprietary boundaries other than through market prices. In either case, the production process is at least partially subtracted from mere market price considerations and geared towards internal or external planning. The first case is more frequently studied within the Anglo-Saxons tradition; the second is more akin to the European experiences; the case of Asia is somehow mixed. To be sure, though, the former strong differences among world regions seemed to have faded in recent years.

To deal with the above complex issues and supply lines for future research, we decided to structure the paper as follows. Section 1 provides the theoretical foundations of fragmentation, ranging the from stylised facts of the first scholarly contributions to the explanation of the core concepts. Section 1 also includes a brand new way to look at industrial districts, namely the use fragmentation as a tool to understand how SMEs network locally. Section 2 critically reviews the empirical literature on fragmentation. Indeed, we firstly isolate those contributions dealing with fragmentation in Europe and secondly those related to Asia, providing elements of similarity and dissimilarity. We also stress the tight connection between fragmentation and intra-industry trade and between fragmentation and vertical intra-industry trade as we take stock of the growing significance of vertical specialisation in world trade. Section 3 and Section 4 are extremely preliminary. Section 3 recalls the key outcomes of the critical reviews provided in Section 1 and 2, in particular by stressing how Europe and Asia experienced different paths of international fragmentation (either through the Market or through the Hierarchy). Section 4 concludes with a stimulus for future research by looking at possible intersections and commonalities among the concepts of fragmentation, Global Value Chains and Global Production Networks. 


\section{Fragmentation: The Theory}

\subsection{Some Stylised Concepts}

In this Section, we look at the theoretical background of fragmentation. The first step is to understand what fragmentation means in the first place, and then identify the reasons why this phenomenon is so significant at global level. Nowadays, trade in parts and components represent a significant and increasing part of world trade. To study this particular phenomenon we thus need to consider 'fragmentation' explicitly and explain why, beside being caused by the tendency of a firm to grow in general, it is sought after to such a great extent. In order to do so we need to find a self sufficient economic rationale for it. Figure 1 depicts, from the upper to the lower level, how firm may move from a vertically integrated production process to a fragmented one. Initially, the good is processed entirely within a single production block before being offered to consumers. Then, we present examples of fragmentation, from simpler to more complex cases.

Figure 1: Vertically integrated production, fragmentation and service links.
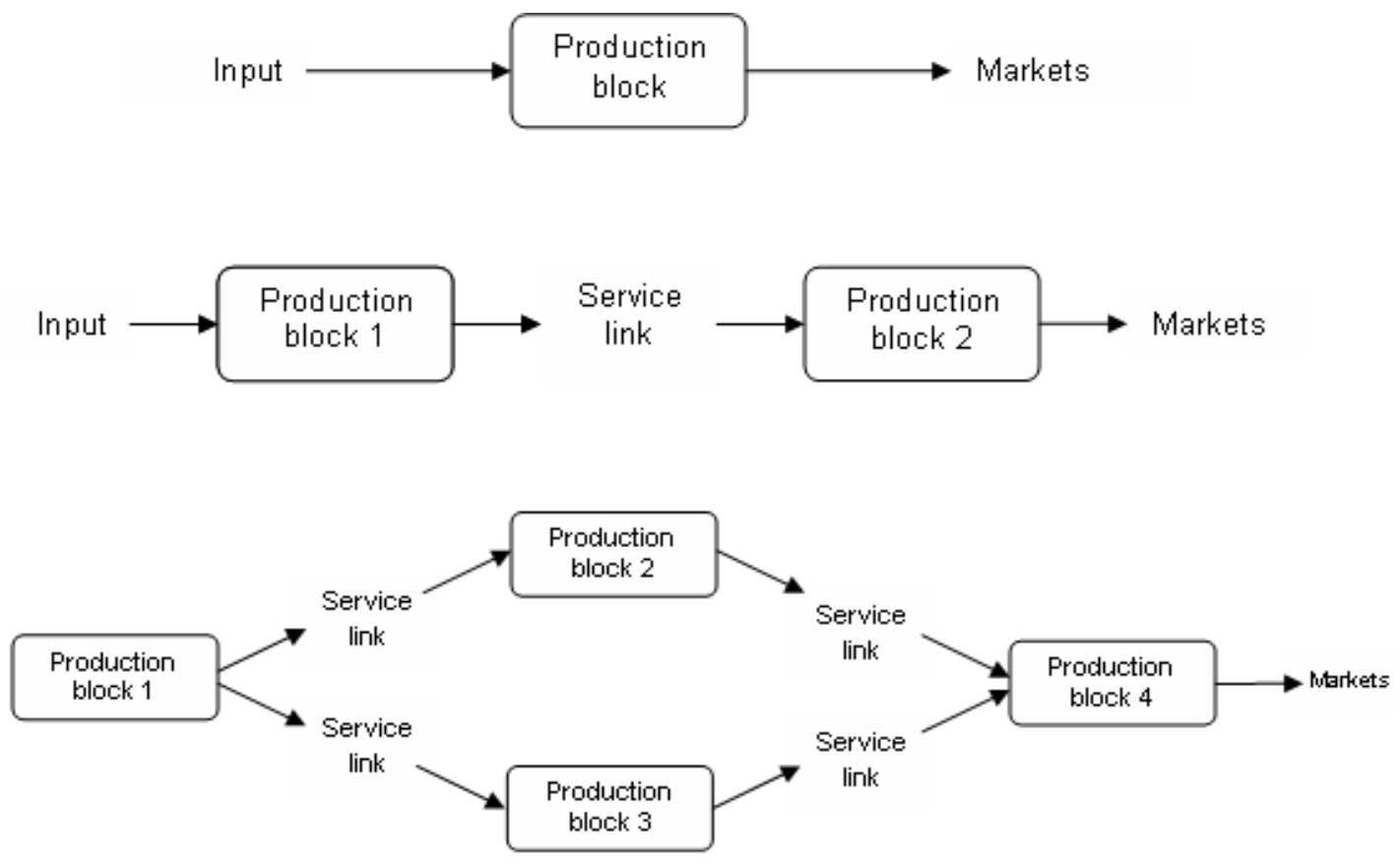

Source: Jones and Kierzkowski (1990 [17])

Clearly, fragmentation may lead to a relatively simple subdivision of production, in which inputs are processed in a first production block to become an output that is input for the next phase, In this perspective, service links are only those needed to connect production blocks, and not those required to supply the product to the final market. Indeed, working with different production blocks implies that intermediates have to be transferred between different manufacturing units, thus transport costs are expected. Disregarding weight issues, transport costs will be higher the greater the distance between the production facilities. Yet, service link costs may increase due to the need for a more complex coordination between production block, for example in terms of delivery times, quantities to be manufactured, and technical specificities. The lowest part of Figure 1 is a clear example of a more complex fragmentation process, in which some production blocks are in charge for further manufacturing whereas some others merely proceed to assembly.

To make fragmentation feasible, some conditions are necessary. Firstly, the production pro- 
cess has to be divisible into independent, geographically separated, production blocks. Secondly, service link costs to connect and coordinate production block activities, do not have to be so high as to delete the cost advantages arising from a better plant localisation. For this reason, it is worth looking into the very nature of service links. Some argue that the dramatic reduction of service link costs, recently achieved thanks to technological advances, is probably the major cause of fragmentation, especially at international level. Let us see how this argument run.

\subsection{From Large to Small: the Disintegration of MNEs}

From a MNE perspective it is possible to consider fragmentation as a form outsourcing. Let us not specify, for the moment, whether this implies a domestic or rather an international connection. We shall return to this argument later on in this paper.

A comparison between the costs incurred by an integrated firm and those incurred by a fragmented one, allows understanding the importance of service links in the selection of the organisational structure and, therefore, why a previously integrated MNE may find convenient to subdivide itself into different production blocks. From the demand side, we can relay upon the long discussed 'love of variety', expressed by the well-known Dixit-Stiglitz utility function, whereas, from the supply side, firms may be assumed to behave in a Chamberlinian monopolistic way, thanks to the existence of internal economies of scale. Within this framework, typical of the so called New Trade Theory, it is assumed that fragmentation leads to the emergence of service links. For the sake of simplicity, it is supposed that such service link costs consist only in those transportation expenses that are needed to transfer intermediates from one production block to another. To begin with, transport costs are assumed to be of the iceberg type: i.e. when shipping a good from one location to another, part of the commodity is lost during the shipment, as it may happen when an iceberg is moved from cold sees to warmer places. The loss caused by the shipment is proportional to the amount of good transferred; therefore, service links show constant returns to scale. Figure 2 depicts this model.

Figure 2: Fragmentation and integration with economies of scale within production blocks.

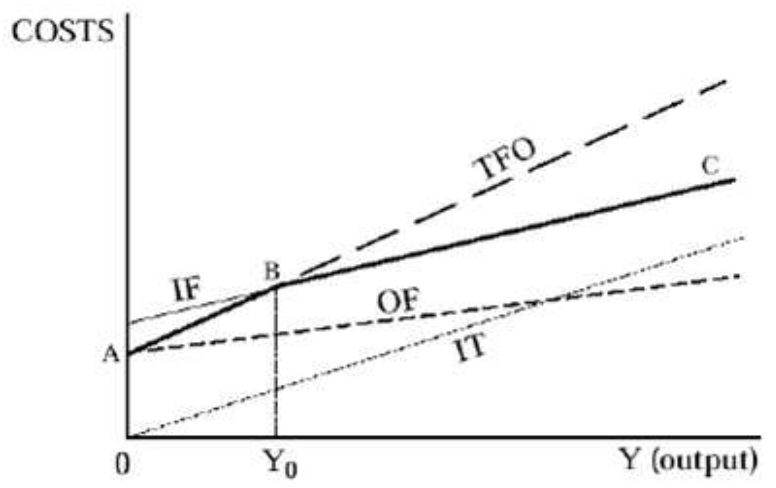

Source: Jones and Kierzkowski (2005 [18])

IT line indicates transportation costs. It starts from the origin and shows a positive slope. The absence of any intercept indicates there are no fixed costs; whereas the positive slope implies that costs are proportional to output. For how it is drawn, i.e. as a straight line, there are also constant marginal costs and constant returns to scale. The OF line, instead, represents production costs of each manufacturing block. The intercept indicates the presence of fixed costs and, therefore, the possibility of achieving increasing returns to scale within each production block. The vertical sum of the two lines IT and OF gives the locus TFO, that represents the total cost of fragmentation for any level of output of a firm. The IF line represents the total costs for 
an integrated firm. It has an intercept on the vertical axis and it has a positive slope too. These features mean that the integrated firm faces constant marginal costs and has increasing returns to scale. We suppose that the IF line is always located above the OF line as it is reasonable to assume that if a firm wishes to minimise its costs, it will locate its production blocks where marginal costs are lower.

The fragmented line $\mathrm{ABC}$ is the locus corresponding to the minimum production costs for any level of output. Therefore, any firm wishing to minimise overall production costs will choose not to fragment its production process if it produces as far as $Y_{0}$. Beyond this threshold, the firm will more conveniently fragment the process.

A change of the initial hypotheses leads to the inclusion of the fragmentation scenario as depicted in Figure 3. Service link, proxied also in this case by transport costs, are not now of the iceberg type, but independent from the level of output. Thus a horizontal line, namely the SL, indicates such costs. Contrary to the previous model, it is here assumed that both the vertically integrated firm and each production block present constant returns to scale, whereas transport costs show increasing returns to scale. The IF and OF lines represent the costs of an integrated firm and the costs of each production block, respectively. Both lines depart from the origin, thus confirming that there are no increasing returns to scale; but the slope shows the presence of constant marginal costs. The OF line is clearly flatter then the IF, as, given a certain output, it is reasonable to assume that the disintegrated firm will choose to locate its production blocks to those places where manufacturing costs are lower. The TFO line, as in the previous case, refers to the total costs incurred by the firm fragmenting its production, whereas $\mathrm{OBC}$ indicates the locus of minimum costs for any level of production.

Within this scenario, if the output level lies between zero and $Y_{0}$, the firm will gain from integration, whereas for higher production levels, fragmentation will be more convenient. The savings obtained by disintegration the manufacturing process are higher than the costs implied by the fragmentation itself.

Figure 3: Fragmentation and integration with economies of scale in service links.

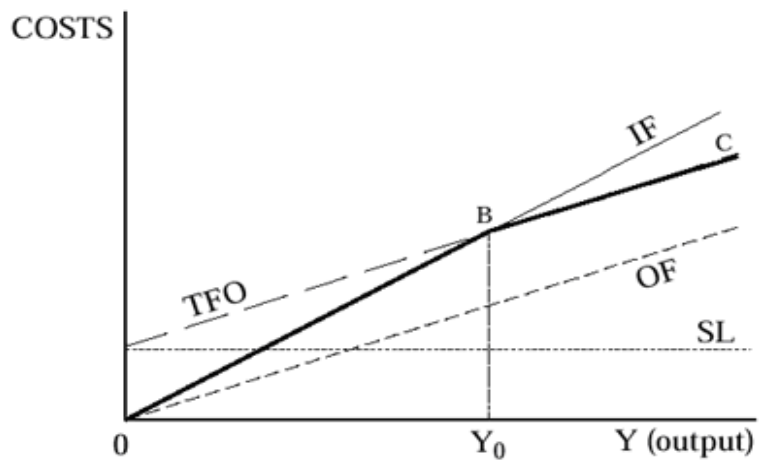

Source: Jones and Kierzkowski (2005 [18])

By comparing the Chamberlinian firm model with the fragmentation model, it is obvious that the initial different hypotheses lead to different results. In the first case, low output levels encourage fragmentation, and high production levels encourage integration. In the second case, instead, fragmentation is induced by higher output levels.

The rationale behind this result depends on the where firms can gain from economies of scale: i.e. from service links or rather from larger production processes.

Results of both models are instead the same if using a comparative static perspective. Consider, for example, a reduction in the costs of service links. In the first model, the IT line will 
show a lower slope, thus the TFO line, expressing total costs, is likely to be flatter. Therefore, the threshold $\left(Y_{0}\right)$ that identifies which one between fragmentation and integration is cheaper, moves to the right: the output value that rules out fragmentation increases. Similarly, in the second model, a lowering of service link costs leads to a drop of the SL line and a downward parallel move, of the same size, of the TFO line. Through these steps, $Y_{0}$ shifts to its left, thus a lower production level is sufficient to prefer fragmentation over integration (Jones and Kierzkowski, 2005 [18]).

The fragmentation model relies on some debatable hypothesis. The absence of positive correlation between service link costs and the output level is doubtful, even though the assumption of constant returns to scale within production blocks seems realistic. Jones and Kierzkowki (1990 [17]), in their seminal contribution, took into account the hypothesis that service links may present increasing marginal costs. This might happen if transportation costs are not completely independent from the shipped quantity, but rise with the volume of goods to be transferred. For fragmentation to happen, it is assumed that the sum of marginal costs in the service link activities with the marginal costs featuring each production block should be lower than the marginal costs incurred by an integrated manufacturing process. This is reasonable if the localisation of each production block allows for a significant reduction in the marginal costs of the fragmented production block. If considering Figure 3, the SL line should show a positive slope with a consequent increase in the slope of line TFO, too. Such a change will push $Y_{0}$ to the right, but the slope of the TFO line should be anyway lower than that of the IF.

\subsection{The First Theoretical Background}

We need now to consider how fragmentation works when incomes and demand for output of a product increase within a vertically integrated firm. Such a model is depicted in Figure 4 below.

Figure 4: Costs of service links and costs of production blocks.

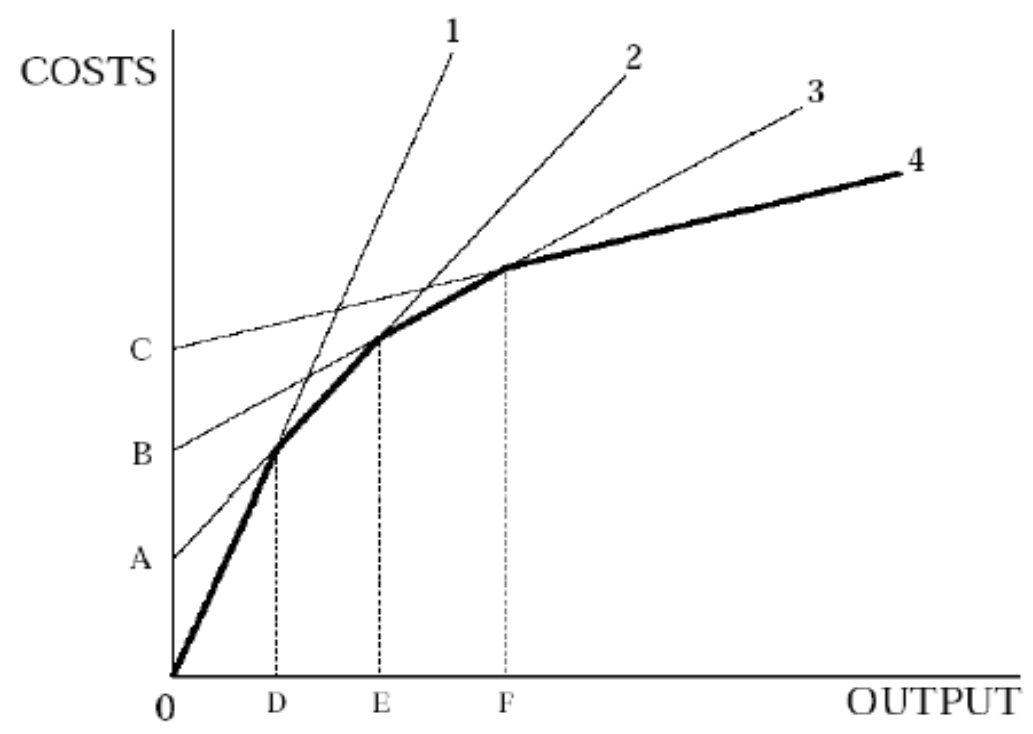

Source: Jones and Kierzkowski (1990 [17])

Ray 1 from the origin describes the costs of production when it is undertook in a single block with constant returns to scale, while segment 2 , with vertical intercept $0 \mathrm{~A}$, describes an alternative process in which two different domestic locations are selected to take advantage of geographic differences in various factor costs and productivities. Such a subdivision could 
serve to reduce marginal costs of production through the exploitation of both absolute and comparative advantages. A Ricardian approach applies when workers in one area of the country tend to have different skills from those in another area, and the skills required in each production block differ so that a dispersion of activity could lower marginal production costs according to comparative advantage. Alternatively, it might be the case that the production blocks differ from each other in the proportions of different factors that are required. Labour-intensive production blocks would then be better located in regions in which labour is cheaper than capital and capital-intensive production in regions in which capital is cheaper than labour. This would be a Heckscher-Ohlin type of comparative advantage. A Smithian perspective may be finally assumed when looking at the absolute advantages that every single sector is achieving from the availability of cheaper factors in a different location.

The use of two locations (rather than one) lowers aggregate marginal costs (as shown by the slope of A2), but their co-ordination requires service links that imply fixed costs, 0A. This would represent outsourcing within the country, and it could imply linking production blocks within a single firm or, alternatively, involve one firm making arm's length arrangements with a different firm in a different location. Clearly, such fragmentation only becomes cost-effective if output levels exceed 0D. Line segments 3 and 4 illustrate the increasing possibilities of decreasing marginal costs if a greater degree of fragmentation is introduced, to take advantage of differences in international factor prices and/or factor proportions among separate fragments. Of course, such international fragmentation raises the costs of service links. The integrated minimum cost schedule is shown by the heavy line, with increases in the degree of fragmentation occurring at output levels D-F. This schedule presents increasing returns to scale.

\subsection{Service link costs: a taxonomy}

We have seen that fragmentation requires various costs including communication costs, transportation expenses to link remotely located production blocks, coordination costs, and so on. Table 1 lists the most notable components of service link costs. We divide the costs mainly into four categories. The first category is made of trade costs, whose subcategories are based on Anderson and van Wincoop (2004 [1]). Transportation costs and policy barriers have long been the subject of many trade economists. Other factors in subcategories, however, remained much less unexplored (Kimura and Takahashi, 2004 [24]). 
Table 1: Components of service link costs.

\begin{tabular}{|c|c|c|c|}
\hline & Category & Subcategory & Details \\
\hline \multirow{17}{*}{ 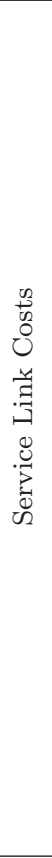 } & \multirow{7}{*}{ Trade costs } & transportation costs & shipment charge, freight charge \\
\hline & & policy barriers & $\begin{array}{l}\text { tariff barriers: ad valorem tariff, specific tariff, non-tariff bar- } \\
\text { riers (quotas, others) }\end{array}$ \\
\hline & & information costs & $\begin{array}{l}\text { search cost for sellers or buyers, research costs for preference } \\
\text { of foreign people }\end{array}$ \\
\hline & & contract enforcement costs & direct and indirect costs to make sure \\
\hline & & $\begin{array}{l}\text { costs associated with the use of } \\
\text { different currencies }\end{array}$ & costs of exchange rate volatility, risk edge and uncertainty \\
\hline & & legal and regulatory costs & $\begin{array}{l}\text { direct and indirect costs to deal with legal regulatory issues } \\
\text { and procedures }\end{array}$ \\
\hline & & local distribution costs & $\begin{array}{l}\text { costs to utilise local infrastructure, and to efficiently deliver } \\
\text { goods to local consumers }\end{array}$ \\
\hline & \multirow{4}{*}{ investment costs } & policy barriers & $\begin{array}{l}\text { indirect costs due to prohibition to entry, absence of national } \\
\text { treatment, and other FDI discriminated measures }\end{array}$ \\
\hline & & information costs & search cost for suppliers \\
\hline & & contract enforcement costs & direct and indirect costs to make sure \\
\hline & & legal and regulatory costs & $\begin{array}{l}\text { direct and indirect costs to deal with legal regulatory issues } \\
\text { and procedures }\end{array}$ \\
\hline & communications costs & & telecommunication costs, internet fee \\
\hline & \multirow[b]{2}{*}{ coordination costs } & timeliness & indirect costs due to inadequateness of time delivery \\
\hline & & uncertainty & $\begin{array}{l}\text { indirect costs due to uncertainty regarding coordination of a } \\
\text { series of activities from production to shipment of end prod- } \\
\text { ucts }\end{array}$ \\
\hline & \multirow{5}{*}{ agglomeration } & networking & IT networking, business networking \\
\hline & & cluster of suppliers & accessibility to suppliers due to agglomeration effects \\
\hline & & cluster of homogeneous firms & externality \\
\hline \multirow{6}{*}{ 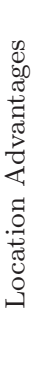 } & & distribution costs & $\begin{array}{l}\text { reduction of distribution costs due to its nature of increasing } \\
\text { returns }\end{array}$ \\
\hline & & $\begin{array}{l}\text { concentration of similar types } \\
\text { of labour }\end{array}$ & availability of workers thanks to agglomeration effects \\
\hline & \multirow[b]{2}{*}{ low production costs } & running costs & $\begin{array}{l}\text { low level of wage, factor abundance (natural resources, land), } \\
\text { accessibility to imported intermediate with low tariff rate }\end{array}$ \\
\hline & & fixed costs & $\begin{array}{l}\text { accessibility to public utility (condition of infrastructure), } \\
\text { availability of productive workers }\end{array}$ \\
\hline & $\begin{array}{l}\text { proximity to large mar- } \\
\text { kets }\end{array}$ & & $\begin{array}{l}\text { proximity to large markets in which there are many consumers } \\
\text { or customers }\end{array}$ \\
\hline & $\begin{array}{l}\text { other geographical fea- } \\
\text { tures }\end{array}$ & & e.g. there is a suitable port for transit trade \\
\hline
\end{tabular}

Source: Kimura and Takahashi (2004, p. 31 [24])

The second category is made of investment costs. A firm that locates production blocks abroad normally operates through FDI. Therefore, any policy barrier and problem relating to FDI adversely affect fragmentation. Indeed, investment-related issues seem particularly important in developing countries, where restrictions are often consistent and often an obstacle for the formation of international production/distribution networks.

The other two components, communications costs and coordination costs, have been much less considered in the literature, in spite of their importance. These costs are associated with the existence of production blocks in more countries. Recently, some components of these two categories have been reduced, thanks to technological progress, while others remain.

There are thus many components in service link costs. Some are relatively easy to evaluate, while others are difficult even to identify. In any case, all components raise transaction costs and hence determine the extent of the formation of international production/distribution networks. Let us now consider two important points. Firstly, components of service link costs can be divided into fixed costs and running costs; nevertheless the demarcation between the two is not always clear. For example, transport costs and telecommunications costs are mostly running costs, while information costs and investment barriers are more akin to fixed costs. The former has been recently declining, due to trade liberalisation and the IT revolution. On the other hand, the latter costs would be persistent. Secondly, the importance of service link costs significantly varies across traded goods. If intermediate goods are traded many times within a network, trade 
costs become more important for trade in parts and components than for trade in final goods.

\subsection{Two-Dimensional Fragmentation: A New Approach}

The original idea behind fragmentation was related to the U.S.-Mexico back-and-forth production sharing, where, typically, an American firm exports parts and components to its affiliates in Maquiladora for assembling and sends the finished products back to the U.S., either to its headquarters or to other affiliates. This phenomenon clearly appears as a typical example of intra-firm, cross-border fragmentation in which firms take advantage of differences in location advantages, such as low wages and low-cost service links. This case is a very simple one, compared to the more sophisticated structures of fragmentation emerging in East Asia. Indeed, there seems to be some kind of new production/distribution networks involving the countries of that region, especially for trade in part and components in machinery industries based on the exploitation of different location advantages. To study this problem Kimura and Ando (2005 [23]) proposed a measure of two-dimensional fragmentation based on geographical distance and on uncontrollability. ${ }^{1}$ The former measure states that differences in location advantages are exploited when the service link costs due to the geographical fragmented production block is overcome, whereas the latter recalls the problems arising when fragmentation goes beyond the boundary of the firm, such as weaker managerial control. In this case the increase in service link costs derives from uncontrollability, whereas "the reduction of production costs is generated by de-internalisation advantages or the counterparts' ownership advantages" (Kimura and Ando, 2005 , p. 318 [23]).

This two-dimensional approach can be portrayed as in Figure 5 in order to emphasise that fragmentation may arise either with (intra-firm trade) IFT and arm's length transactions.

Figure 5: Two dimensions of fragmentation.

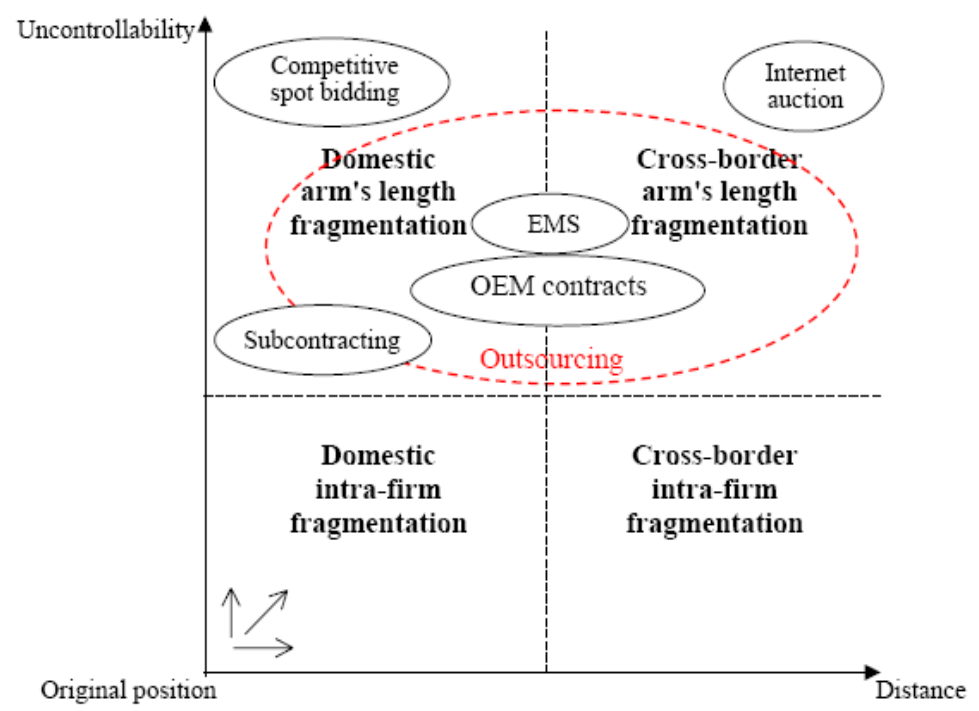

Source: Kimura and Ando (2005 [23], p. 319)

One axis represents "physical distance" between the original position and a new location of the fragmented production block. Clearly when the distance is short and the fragmentation is within the national border, this case can be labelled as "domestic fragmentation", otherwise it will be "cross-border fragmentation". The other axis denotes the concept of "uncontrollability"

\footnotetext{
${ }^{1}$ The concept of uncontrollability is replaced with that of disintegration in a more recent work of Ando and Kimura (2006 [3]).
} 
described above. Once the fragmented production block is beyond the boundary of the firm, the relationship becomes arm's length and it could be characterised by different degrees in controllability: long-lasting outsourcing arrangements or subcontracting agreements might present a significant level of controllability, whereas competitive spot bidding and internet auctions show the lowest controllability.

The Authors studied the same phenomenon one year later (Ando and Kimura, 2006 [3]), by looking into the nature and the evolution of service link costs along uncontrollability (now disintegration) and distance, as indicated in Figure 6.

Figure 6: Another perspective of two-dimensional fragmentation.

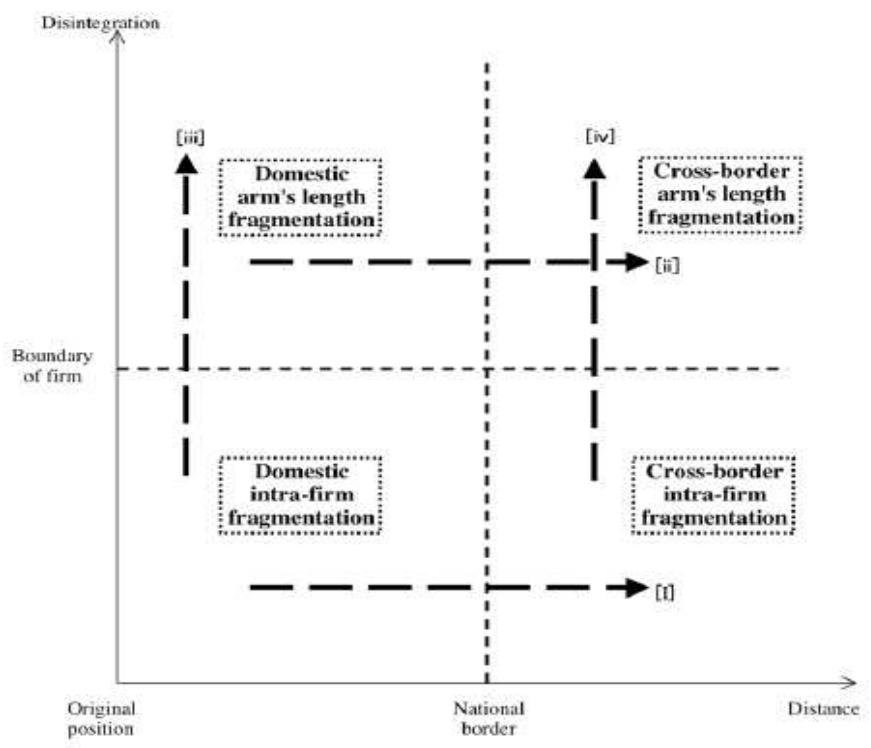

Source: Ando and Kimura (2006 [3], p. 21)

We already pointed out that the economic elements determining service link costs and production costs are different between fragmentation along the distance axis and along the uncontrollability axis. More specifically, if looking at fragmentation in terms of distance, there seems to be nothing new, compared to the previous contributions stressing the role of transport, communication and intra-firm coordination costs (indeed the arrows [i] and [ii] in Figure 6 show the increase of service link costs due to distance from the original position). Conversely, location advantages are the most important determinants that could lower the overall production costs, such as the usual wage level differentials, factor/resource availability, technology transferability, but also infrastructure services and the procurement of parts and components as well as host country's policies.

Considering, instead, fragmentation along the controllability axis, additional service link costs may arise from the loss of controlling grips over the fragmented blocks. They include costs caused by incomplete information, lack of credibility, as well as the costs of losing contracts without effective/efficient dispute settlement mechanisms (see the arrows [iii] and [iv] in Figure 6). On the other hand, lowered marginal production costs may come from the counterpart's ownership advantages, that is when the business partner has a better technology and/or a special managerial ability in some production process; in this case outsourcing may reduce total production cost (see Figure 6).

The emergence of strong economies of scale in the service link costs is one of the channels that induces fragmentation over agglomeration: production blocks by many firms tend to be placed where service link costs are low. This channel is particularly significant when the host country 
for fragmented production blocks is a developing country, whose main steps towards progress include improvement of economic infrastructure and policies to protect the environment.

Another channel is to use arm's length fragmentation alongside agglomeration: indeed some transactions, such as procurement of customised parts and components, require frequent changes of product specification as well as different delivery times, suggesting a close location between upstream and downstream firms. If there are strong increasing returns to scale in service links, this is likely to lead to strong fragmentation and high disagglomeration at firm level, but this will result in agglomeration at meso (aggregate level). In other words, once agglomeration emerges, it becomes one of the strongest location advantages. Much more attention should be devoted to this topic: indeed Jones and Kierzkowski (2005 [18]) emphasised that the process of international fragmentation may not necessarily lead to disagglomeration, but rather to further agglomeration.

Eventually, "once the critical mass of agglomeration is formed, it becomes one of the important elements of location advantages for individual firms considering fragmentation along the distance axis. At the same time, the existence of various kind of potential business partners generates opportunities for fragmentation along the uncontrollability axis. Such environment also nurtures indigenous firms penetrating into international production/distribution networks once they gain competitiveness" (Kimura and Ando, 2005, p. 322 [23]).

A specification is nevertheless required on the nature of the service link costs arising, in this new framework, both along the disintegration and the distance axis.

When a firm decides to introduce intra-firm fragmentation, at industry level, fragmentation and agglomeration may coexist. Indeed the concentration of fragmented production blocks occurs at least through two different channels (Ando and Kimura, 2006, p. 8 [3]).

- Both kinds of service link costs are not monotonic, and local minimal points of service link costs tend to attract a large number of production blocks. These costs seem to be of particular significance in cases of less developed countries, where each location meets a different investment climate.

- The concentration of production blocks may also take place due to the close relationship between the service link costs along the disintegration (uncontrollability axis) and geographical proximity as indicated in Figure 5. Obviously, the closer the distance with business partners, the smaller the service link costs in searching potential business partners, managing product quality, delivery timing, monitoring, and others. The northwest area in Figure 7 is a typical example of this kind of agglomeration: here the concentration of production blocks would lead to a reduction in the service link costs, and, this would further attract other production blocks. 
Figure 7: Two kinds of service link costs.
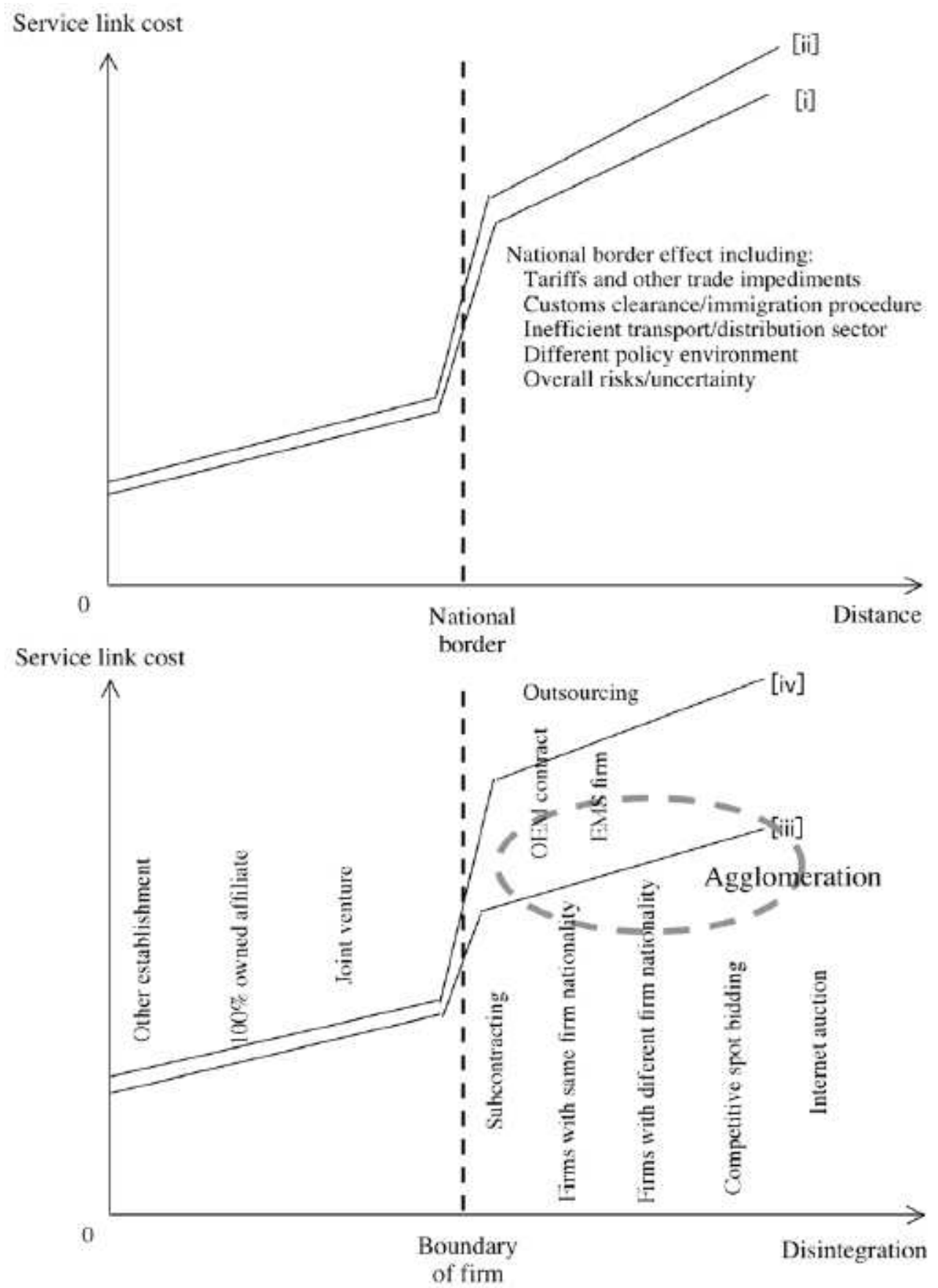

Source: Ando and Kimura (2006 [3], p. 22)

\subsection{From small to large: the networking of SMEs}

The typical sequence experienced by Anglo-Saxons and Japanese MNEs, ${ }^{2}$ starts from vertical integration, followed by international fragmentation, and eventually to horizontal agglomeration,

\footnotetext{
${ }^{2}$ This is the case of chips, that enter as input in several manufacturing processes, ranging from the computer industry to the automotive sector. Clearly, the lower the specificity of the intermediate, the higher the chance that the "incoming" industry is able to serve different productions.
} 
whereas the formation of industrial clusters of SMEs, exploiting economies of agglomeration, is closer to the experience of continental Europe, but also detectable all around the globe, included Asia and the US.

In the first case, fragmentation of large MNEs might also lead to the creation of industrial clusters in those regions where production blocks are placed. This is the case of East Asia, where SMEs are involved in the disintegration of production. When dealing with arm's length fragmentation, SMEs may consider the costs to collect information, understand local laws and deliver to the foreign market too high, in comparison with local firms. This is not true when the distance with business partners is lower and, therefore, service link costs are lower. This happens in searching potential business partners, consulting detailed specs of products, managing product quality and delivery timing, solving disputes over contracts, monitoring. All these elements, that we already discussed in the previous Sections, induce agglomeration and may lead to the creation of a cluster of firms. When a cluster has emerged, it often leads to further agglomeration.

In the second case, in some European countries, especially in Italy, but elsewhere as well, industrial districts and the so-called local systems of production, historically represented a significant feature of the national economic systems. The formation of industrial districts specialised in the production of a number of traditional products (textile, footwear, chairs, musical instruments, gloves, etc.) was said to be based on the share of a common knowledge, a certain degree of socialisation of production, and a process of de-localisation from the most advanced industrial areas, once dominated by the large firms, who were put under strain by social unrest and diseconomies of scale. In general, the success of Italian industrial districts - it was agreed - derived from having been able to generate network economies as a result of a virtuous mix of cooperation - on price setting - and competition - most notably in quality. This optimistic vision came to an end by the late '90s, when external competition, especially from east Asia, but also from other developed countries, put districts under a strong pressure. Taken separately, each district firm was unable to reach an adequate size to generate internal economies of scale and found it difficult to reach final markets, without the help of other connecting firms. The need to face domestic and international competition forced local enterprises to create some tools to improve their market power. This happened through the formation of associations and/or organisations (such as consortia), whose objective was to develop economies of scale and create networks in production and distribution. Through these means the industrial district managed to become, in some cases, an "integrated system of production", behaving - to some extent - as if it was a single enterprise. ${ }^{3}$

\section{Fragmentation: The Empirical Evidence}

A recent work of Jones, Kierzkowski and Lurong (2005 [20]) checks the validity of the typical hypothesis arising from international fragmentation, i.e. income growth, as well as lower prices of service links, will lead to more fragmentation and more trade in parts and components. Thanks to the database available in Ng and Yeats (2003 [34]), the Authors are able to study the relationship between trade in parts and components, GDP and average business connection charges, where each variable is referred to for NAFTA, EU and East Asia. According to the econometric estimation, all variables show the expected sign. Specifically, income coefficients have a positive and highly significant sign, whereas those related to service link costs are correctly

\footnotetext{
${ }^{3}$ Within the industrial district, firms experience the share of knowledge, together with a concentration of excellence on one hub of the network. This concept derives from the abundant literature on local production systems whose overall study goes beyond the aim of this paper. Indeed, we wish to provide here just the connections between this latter strand of scholarship and those phenomena, collaterally studied by fragmentation, that emerge when different SMEs integrate either vertically or horizontally. Actually, even though fragmentation concentrates on horizontal agglomeration deriving from the disintegration of a MNE, the evidence of Italian districts more frequently is concerned about vertical integration.
} 
negative and almost all extremely significant. ${ }^{4}$

These results allow the Authors to test the power of the fragmentation theory against the new economic geography. According to the first approach, disagglomeration is to be expected in the global economy, when it becomes larger, whereas the latter strand of literature conveys a message that agglomeration is the norm in the presence of increasing returns to scale in manufacturing when the scale of output increases. In this case disagglomeration prevails but this should not be considered as a final result. Indeed, even though it has been often stated that international fragmentation leads to disagglomeration, Jones and Kierzkowski (2005 [18]) admit that this could not happen. In fact the presence of similar fragments of production across industries may be aimed at improving technological and wider manufacturing abilities. This is for example the case of electronic chips, which enter a wide spectrum of production processes. The same can be said about the relationship between arm's length fragmentation and agglomeration for the electric machinery in East Asia (Kimura and Ando (2005 [23]); Ando and Kimura (2006 [3], $2007[4])$.

\subsection{Fragmentation in Europe}

Baldone, Sdogati and Tajoli (2001 [8]) were among the first to present an empirical study on the outsourcing of textile manufactures in the CEECs by firms located in the Western European Countries. Focusing on fragmentation among countries, they assumed that the original producer retains property rights over the intermediate products supplied to the subcontractor. Empirically, they employ detailed trade data on outward processing trade ${ }^{5}$ as a proxy for fragmentation, whereas theoretically they need to specify the "comparative advantage" concept for segment specialisation. They suppose that EU firms do not chose to operate in countries simply on the basis of pre-existing comparative advantages, but rather, on a more complex reasoning, that sometimes goes beyond a sheer cost evaluation.

Baldone, Sdogati and Tajoli (2001 [8]) find support to this hypothesis. They develop a regression model where the value of EU re-imports from a given country over the total value of re-imports from the CEECs is the endogenous variable, whereas the explanatory ones include wages in the CEECs, a set of variables used to indicate geographical and economic proximity between trading partners, and some other variables representing CEECs' characteristics that may favour location abroad of textile and apparel production. Results show that labour costs, along with geographic and cultural proximity, are the most important reasons for choosing a given country as a processing area. ${ }^{6}$ However, one has to remember that once a firm finds a partner in a low wage country, factor cost evaluation is not the only point of reference. This perspective is sometimes confirmed for those Italian firms that have been searching for lower production costs, to face the competition of new-comers from developing countries in mature sectors, but not for those German firms, for example, that invest in the CEECs in order to better concentrate in the upstream phases of their value chain, where higher value added activities are more feasible and appropriate for their own competitive advantage. To distinguish between the two strategies, one has to look, indeed, not merely at the factor-cost saving of a decentralised piece of production (which may be common to both strategies) but rather at what a firm had in mind in the first place, i.e. whether this move is a mean to the end of upgrading its positioning or rather a defensive attempt to face aggressive new-comers on their terrain.

In any case, the final outcome of this research seems to confirm that once the processingabroad practice has started, EU firms tend to concentrate in the up-stream segments of their

\footnotetext{
${ }^{4}$ Equivalent results are shown by an equation where the explanatory variables are the same of the previous regression whereas the endogenous one is given by the ratio between the amount of trade in parts and components and the whole trade exports pertaining to a particular region.

${ }^{5}$ Data on outward processing trade are from Eurostat, Comext CD-Rom, Intra-and-Extra-EU trade, classified according to the Combined Nomenclature.

${ }^{6}$ Baldone, Sdogati and Tajoli (2002 [9]) obtained similar results in a later study.
} 
production process, rather than simply moving labour intensive segments to countries with lower labour costs for defensive reasons. In this 'vertical re-integration' in the processing country, FDI may be playing an important role as they allow, through proprietary control, for a tighter supervision of both processes and products. The nature of fragmentation in the textile/apparel industry between EU and CEECs has been studied in details. Specifically it seems that fragmentation emerges both through arm's length transactions as well as by setting new plants abroad, thus increasing IFT flows. In any case, the results obtained by Baldone, Sdogati and Tajoli are consistent with those reached a few years later by Ando and Kimura (2007 [4]) when studying how manufacturing MNEs operates in CEECs through their affiliates.

Another interesting perspective, when studying fragmentation, is the one linking the studies of local production systems to their international expansion. Without entering into much details, what can one say about the relationship between the fragmentation of large firms and the agglomeration of SMEs? Are perhaps fragmentation and agglomeration parts of a dual phenomenon? Something like the two sides of the same coin? The answer is not in the affirmative, as MNE's tend to operate mostly via FDI, while SME's - according to the majority of studies tend to prefer collaborations and other, indirect, forms of internationalisation, such as non-equity investments, joint ventures, technology transfers and a number of long term binding contracts. In a nutshell, larger firms, particularly MNEs, tend to operate in the CEECs through their own affiliates, whereas the traditional features of SMEs, characterised by limited managerial and financial resources, are most likely to experience different pattern of external growth and various forms of collaborations with connected firms. So, in general, the rule is that, given the variety of firms size and strategies, the growth of connected activities across international boundaries and across firm's boundaries may follow different patterns: i.e emerge from horizontal and/or vertical integration, ${ }^{7}$ collaborative agreements, or pure market transactions.

By entering the local territory as a key variable, Corò, Volpe and Bonaldo (2005 [11]) go beyond this perspective and try to understand the mechanisms underlying the international fragmentation of Italian production systems. They draw on the theoretical framework introduced by Jones and Kierzkowski, but suggest a more eclectic approach. In particular they build on the vast literature about the so called 'industrial districts' as well as the most recent contributions on the global value chains (Gereffi, Humphrey and Sturgeon, 2005 [15]).

In their work, the specific division of labour inside the so called 'local production systems' is explicitly considered to study fragmentation as a form of SMEs integration. They suppose that it is the local market - rather than the market in general - that plays a crucial role in this respect. This role emerge: 1) in the organisation of the supply chain; 2) in the integration of different production phases; and 3) in the correct match between the demand and supply of intermediate goods. An additional hypothesis is that SMEs develop international linkages on the basis of the local division of labour.

The technical possibility of dividing the value chain, together with variability and the dimension of intermediate markets, lead to the emergence of highly specialized local systems, trough the exploitation of local based externalities. District firms soon became leaders in their markets, even in mature ones, by mixing competitive and cooperative behaviours. In doing so they are often able to reach a very good performance in innovation activities, in the introduction of new products, in the formation of new knowledge and in the creation of new employment. Unfortunately industrial districts had to cope - recently - with a growing foreign competitive pressure, which imposed a redefinition of their positioning in the global markets. They were forced to increase their efficiency and gain access to new knowledge. In particular, Corò, Volpe and Bonaldo investigated whether the local productive fragmentation may have helped firms to replicate the home model overseas. The Authors argued that in the international disintegration of production,

\footnotetext{
7 "... the productive integration is vertical when the flows of goods between two economic regions regard two consecutive phases of the same supply chain (i.e. export of tissue and import of apparel between Italy and Romania)". (Corò, Volpe and Bonaldo, 2005, p. 8 [11]) Horizontal integration is said to take place, instead, when final goods are produced overseas to be exported into final markets.
} 
the Italian industrial districts tend to use less resource intensive tools and less FDIs, preferring to embark in productive agreements and market transactions, involving less capital but more trade flows of intermediate goods. By analysing bilateral trade flows, they managed to assess the dimension of the fragmentation process, by looking at regional and provincial data. Despite being very different both in their pattern and trends, regional and provincial trade flows confirm the existence of a significant level of integration between some Italian areas and CEECs, as well as with China and India. But, the former is typically of the 'vertical type', while the latter is typically of the 'horizontal type' (see footnote 6). This is to say that Italian firms tend to delocalise just a few labour intensive phases of production to CEECs, for semi-finished products to be further re-imported, and much more integrated pieces of production to the Far East, in order to serve the final markets (either domestic or foreign).

The growing amount of trade in parts and components between EU member states and some CEECs is also at the basis of the empirical work by Kaminski and $\mathrm{Ng}$ (2001 [119]). They used a revealed comparative advantage index, $R C A_{i j}$, for a component $j$ of country $i$, specified as follows:

$$
R C A_{i j}=\frac{\frac{x_{i j}}{X_{i}}}{\frac{x_{j}^{E U}}{X^{E U}}}
$$

where $x_{i j}$ is country $i$ 's exports of component $j$ to the EU; $X_{i}=\sum_{i} x_{i j}$ is country $i$ 's exports to the EU; $X_{j}^{E U}=\sum_{j} x_{i j}$ is EU's total "external" exports of a component $j ; X^{E U}=\sum_{i} \sum_{j} x_{i j}$ is EU's total external exports of manufactures (Kaminski and Ng, 2001, p. 24 [21]). "If the index for a product exceeds unity, a country is said to have comparative advantage in the production of good $j$ because this sector is more important for this country than for EU exporters. If the $R C A$ index is below one, the country has a comparative disadvantage in EU markets for a good j" (Kaminski and Ng, 2001, p. 24 [21]).

Such an index is used to study the level of integration experimented by CEECs in the international fragmentation of production originated in Western firms, over the years between 1989 and $1997^{8}$. First results showed that:

- most CEECs have made significant efforts in becoming competitive in EU markets for parts. Although only two countries (Estonia and Hungary) had $R C A$ index exceeding unity in 1997, there was a significant increase in the values of $R C A$ indices over 1989-1997 for other CEECs except Bulgaria;

- while no revealed comparative advantage in assembling was found in 1989, the Czech Republic, Hungary, Slovakia and Slovenia acquired it in 1993, and Poland and Estonia in 1997;

- the values of $R C A$ both on imports and exports for some CEECs is similar to Malaysia and Mexico's, countries that are highly integrated in the world production through Japanese and U.S. MNEs respectively. This data seem to provide a positive prospect for the economic development of CEECs in the enlarged Europe. ${ }^{9}$

A deeper investigation on the evolution of important sectors showed a strong process of integration in the furniture value chain for most CEECs, whereas the automobile industry fragmentation involves only the Czech Republic, Hungary, Poland, Slovakia and Slovenia. Some

\footnotetext{
${ }^{8}$ Data are from the UN COMTRADE Statistics.

${ }^{9} \mathrm{~A}$ high level of integration with EU economy is shown by the producers of Czech Republic, Estonia, Hungary, Slovakia and Slovenia. Latvia and Lithuania appear yet to take advantage of opportunities offered by fragmentation of production.
} 
involvement is also shown in the office equipment and telecommunications by Estonia and Hungary. Significantly, it is possible to define two different groups of countries on the basis of their comparative advantage. The first tier of CEECs economies (Czech Republic, Estonia, Hungary, Poland, Slovakia and Slovenia) obtained high levels of integration, whereas the second tier (Bulgaria, Romania, Latvia and Lithuania) appeared much less integrated. Indeed countries like Czech Republic and Hungary accounted for one fourth and one third respectively on the total trade of CEECs towards EU, as compared to the meagre $4 \%$ of Bulgaria or $10 \%$ of both Romania and Lithuania.

\subsection{Fragmentation in East Asia}

Fragmentation of production in Europe appears quite simple, because only two different paths emerged. On one hand, EU countries locate some production blocks in some CEECs, paving the ground for intra-firm and arm's length transactions, re-importing intermediates, and most often, finished products to offer to the most developed market. On the other hand, yet on a smaller scale, EU firms also carry out highly-skilled production stages for American firms.

A similar phenomenon takes place between Mexico and the U.S., where American firms export parts and components to their Mexican affiliates, which assembly, and eventually export final products back to America.

East Asia is actually an area where fragmentation shows major complexity. A first example of the sophistication of the Asian model can be seen by comparing Figure 8 with Figure 9, showing, respectively, the U.S.-Mexican case and the international expansion of Japanese MNEs. 
Figure 8: The typical maquiladora operation by the U.S. MNEs: an illustration.

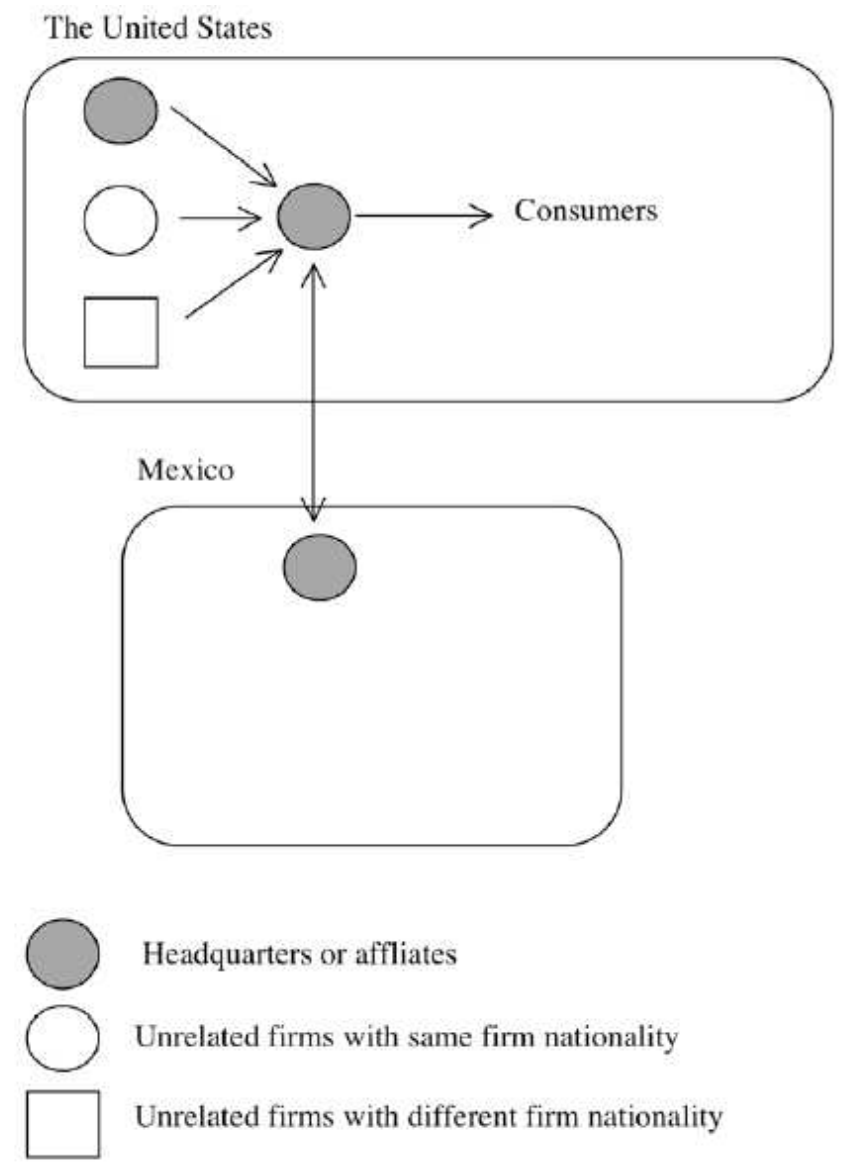

Source: Ando and Kimura (2006 [3]) 
Figure 9: The typical East Asian operation by Japanese MNEs: an illustration.

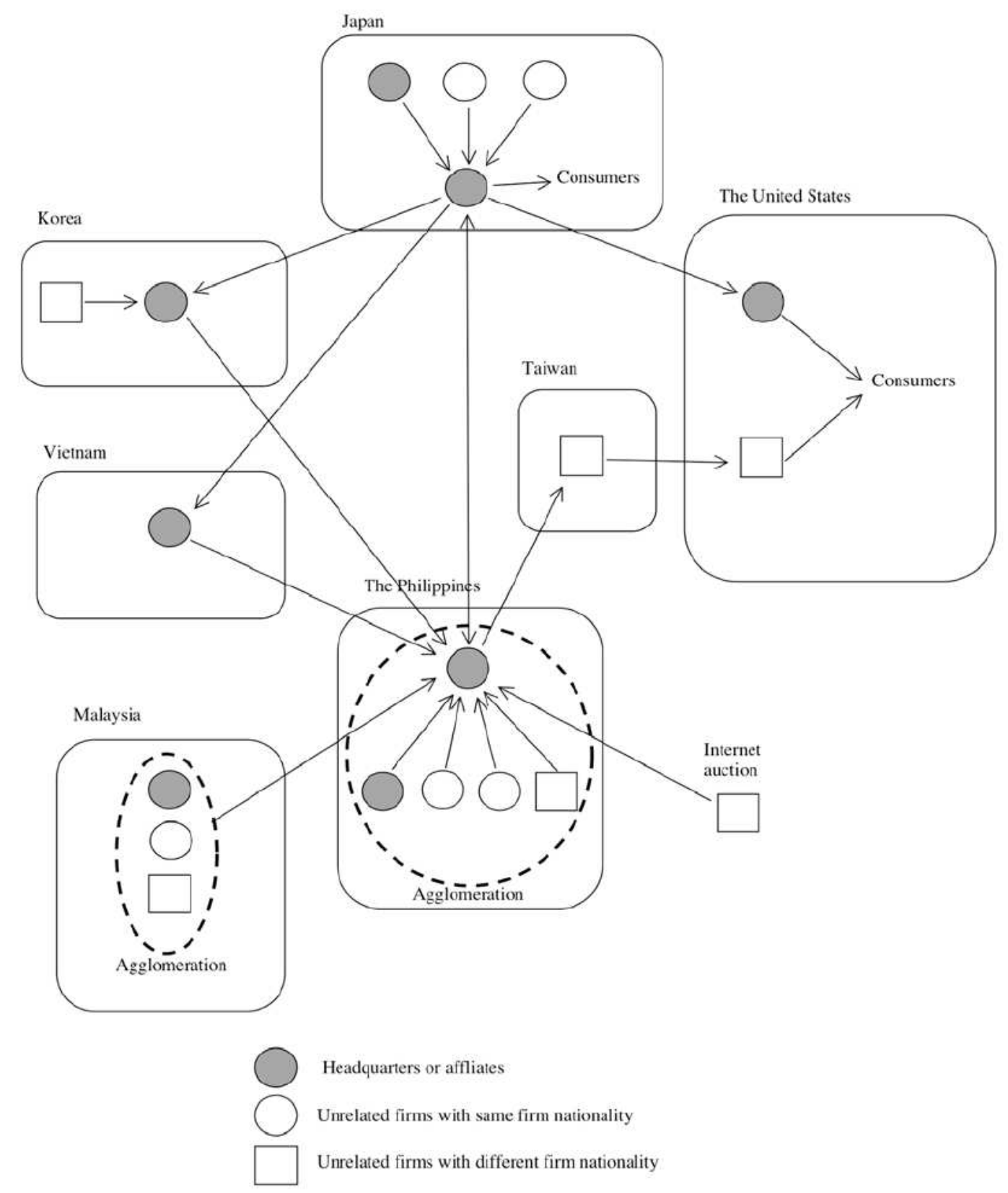

Source: Ando and Kimura (2006, pp. 19-20 [3]) 
In general, fragmentation mostly involves the textile and the machinery industry. The former plays a major role in Europe, whereas the latter is instead of greater significance in Asia. This latter region, indeed, experienced faster export growth than any other part of the world in machinery parts and components, which rose by more than 500\% during the period 1987-2003. As a result, in East Asia the share of exports in parts and components increased from $17 \%$ to $27 \%$ and the share of exports in machinery goods rose from $34 \%$ to $48 \%$,. In general, East Asia's share of world trade increased from $8 \%$ in 1997 to $25 \%$ in 2003.

East Asia intra-regional trade also grew substantially, thanks to a process of deep economic integration. Even though fragmentation of Japanese MNEs involves a great number of firms, there is also some evidence of fragmentation of SMEs, both from Japan and East Asia as a whole. Indeed, Japanese companies with less than 300 regular workers have greatly contributed to the expansion of manufacturing activities, especially in developing Asian countries. This is confirmed by the fact that more than $40 \%$ of Japanese firms investing in East Asia are SMEs, whereas the shares are much lower in North America and Europe (Kimura, Takahashi and Hayakawa, 2007 [25]).

Yet, production and distribution networks in East Asia differ with those of other areas because of several reasons. Just to mention a few:

- they are very important in each economy of the region;

- they do not involve just some countries, but the majority of countries in Southern Asia;

- they are very complex, as they include both arm's length and intra-firm transactions, depending on a number of elements we will try to outline below;

The reduction in service link costs is probably at the basis of this phenomenon. Indeed, favourable environments for FDI in the region, a reduction in tariffs, as well as good infrastructures, were all significant determinants in the economic development of the Asian region.

Many countries in the area pursued export-oriented policies, allowing for the rise of FDI in all sectors of the economy.

The reduction in tariffs and duties, especially those on machinery parts and components, allowed SMEs to participate to international production networks. This occurred through the reimbursement of taxes paid on goods sent abroad to be processed and then re-imported, in a somewhat similar vain to what happens in Europe with the outward processing trade.

As concerns infrastructures, the area experienced great progress in maritime transportation as well as in airport connection.

The great significance gained by fragmentation in the area had important effects in the structure of intra-regional trade. We stressed how the machinery sector was the industry leading the process of fragmentation. Statistics registered a great rise in the volume of IIT, that reached almost half of regional trade in 2002. Trade in final products loose weight and trade in parts and components rose, as we will discuss in the next paragraph.

\subsection{Fragmentation and IIT in General}

Just recently some scholars paid attention to the linkage between fragmentation and two-way trade. For example, Jones, Kierzkowski and Leonard (2002 [19]) showed that international fragmentation often leads to the exchange of components within a vertically integrated production process. If these fragments are classified in the same industry they will lead to trade that is certainly intra-industry and possibly intra-firm.

Jones, Kierzkowski and Leonard (2002 [19]) studied this phenomenon in the television, automotive and apparel industries.

The production process of colour televisions is broken down into two different phases, i.e. the production of colour tubes and the assembly of television set. The former requires significant 
capital investment and is usually carried out in plants located in the U.S.A., whereas the latter takes place in Mexican plants, thank to lower labour costs. This division of labour makes U.S. firms to export a growing amount of cathode-ray picture tubes to Mexico, much higher than Mexican exports of cathode-ray picture tubes towards U.S.A. When considering television sets, instead, the opposite applies: Mexico becomes a net exporter, sending to the U.S. more than ten times the value of television sets to the U.S.A. than are sent in the opposite direction. The latter is a clear indication that the production of television sets is characterised by back-and-forth transactions.

As a result, the overall amount of IIT for the whole sector is high (65\%), and increased over time, whereas the data concerning both cathode-ray tubes and television sets are low. Thus, according to the Authors, data on IIT would be misleading to understand the inner features of the sector as a whole. More correct would be to interpret trade between the U.S.A. and Mexico on the basis of a classical Heckscker-Ohlin framework, with more emphasis on factor proportion and factor prices. ${ }^{10}$

A similar phenomenon regards the automobile industry in North America, where specialisation in types of production process by region has been justified by the differences in the costs of inputs, namely labour costs. This is especially the case of Mexico that now dominates the production of engine castings and wire harnesses, which are both labour-intensive. If looking at data on IIT the level of two-way trade for the whole sector it decreased from a $90 \%$ level at the beginning of the ' 90 s to $61 \%$ of 1999 , whereas trade in parts rose from $67 \%$ to $85 \%$. This scenario is thus different from the one concerning the television sector, whose fragmented nature did not appear from the data, as fragmentation now does appear in the statistics of IIT.

Mexico is also a destination for the fragmentation of production in the apparel industry. Thanks to the Caribbean Basin Economic Recovery Act that allowed for the creation of free trade zones, U.S. firms tend to rely heavily on these facilities for the labour-intensive operations in order to take advantage of lower labour costs. Significantly, the labour-intensive types of apparel actually show the greatest growth in production sharing, thus suggesting that American firms locate their production fragments mainly on the basis of their relative capital and labour intensities.

In the study of North American trade flows we need to pay attention to Canada, that is, after the U.K., the second largest destination for U.S. FDI and, together with Mexico, the other top production sharing partner with the U.S.A. The high degree of integration in the automobile, aircraft and other industries is suggestive of the substantial contribution of fragmentation between the U.S.A. and Canada. An interesting example regards trade in aircraft. Indeed, if looking at IIT measures, the digits of the industry has a whole hide the true nature of two-way trade, that is $81 \%$ in 1999 compared to a $51 \%$ of IIT just in final goods. Considering, instead, parts and engines IIT measures reach $95 \%$ and $92 \%$, respectively. This reflects the scattering of production fragments across the U.S.A. and Canada. ${ }^{11}$

\subsection{Fragmentation and VIIT}

Whereas the previous Subsection focused on the linkages between fragmentation and two-way trade in general, this Subsection considers to what extent the international disintegration of production processes might be empirically related both to (horizontal intra-industry trade) HIIT and (vertical intra-industry trade) VIIT. Indeed some scholars paid attention to the link between VIIT and fragmentation with particular reference to East Asian production networks (Ando, 2006 [2]; Athukorala and Yamashita, 2006 [7]).

From a theoretical viewpoint, VIIT 'models' told a sort of "quality ladder" story in which high-income countries export high-price, high-quality products, whereas low-income countries

\footnotetext{
${ }^{10}$ Nevertheless, and as stated above, the Ricardian comparative advantage cannot be neglected.

${ }^{11}$ Conversely, the fragmentation of production process involving the semiconductor industry does not appear from the available data, that just only show high levels of IIT at aggregate level.
} 
export low-price, low-quality products. Therefore, most empirical studies on VIIT normally consider vertically differentiated products as emerging only from differences in product quality.

But this is just a part of the story. According to Ando (2006 [2]) for example, unit price differentials outside a certain range can be interpreted not only as reflection of differences in quality, "but also of back-and-forth transactions with value-added embodied in vertically fragmented production processes. Thus, the trade pattern categorised as VIIT in our decomposition-type threshold method could reflect international fragmentation within the same commodity category" (Ando, 2006, p. 269 [2]). As a matter of fact, the exchange of products in vertically fragmented production processes may not regard the same industry. Consider the exchange of goods belonging to different categories of the same industry as well as back-and-forth transactions in vertically fragmented production processes, when commodity categories change between imports and exports due to operations: in Ando's words, these are typical examples of one-way trade.

Ando (2006 [2]) considered highly disaggregated data on machinery trade taking place in East Asia from the beginning of the '90s until 2000. Specifically, she computed measures of both horizontal and vertical intra-industry and one-way trade for each machinery sector, i.e., general machinery, electric machinery, transport equipment and precision machinery as well as for machinery trade as a whole. Moreover, and most importantly, she was able to identify trade flows in intermediates and parts taking place within the above commodity groups.

The empirical analysis showed five main results.

1. The significance of VIIT rose sharply, whereas the digit of one-way trade for overall machinery declined. At the beginning of the '90s the share of one-way trade was around 40-50\%, with higher values expressed by Indonesia, and lower values by Hong Kong and Singapore. These figures decreased by a half in 2000 in most East Asian countries. As a whole, the increase in IIT was due mainly to the sharp increase in VIIT, except for Korea and Singapore.

2. The share of VIIT in machinery parts and components increased more rapidly than that of VIIT in machinery products as a whole.

3. HIIT in machinery parts and components does not appear to be very important in East Asia (except for the Philippines and Korea), contrary to what happens in Western Europe, and the United States.

4. The sharp increase in VIIT was largely due to the expansion of back-and-forth transactions in vertically fragmented production processes, in addition to IIT in quality-differentiated commodities.

5. In the transport equipment sector, in which one-way trade is the main pattern of trade, VIIT has gained significance through the years especially for parts and components trade. According to Ando (2006 [2]) the prevalence of one-way trade may reflect import substituting policies in many developing countries.

Results thus confirm the inconsistency of the "quality ladder" hypothesis driving VIIT. Indeed most VIIT in lower-income countries does not systematically involve commodities with export prices lower than import prices and most VIIT in higher-income countries does not involve commodities with export prices higher than import prices. Indeed, some higher-income countries import goods that are more expensive than those that they export; and some lowerincome countries export products that are more expensive than those that they import. This is a clear confirmation of the importance of back-and-forth transactions in vertically fragmented production processes.

This kind of phenomenon is quite similar to the one experienced by Western European countries in their building of production networks in some CEECS, especially those outside the 
European Union, or at least, in the latecomers, as Bulgaria and Romania. Kaminsky and $\mathrm{Ng}$ (2001 [21]) found indeed a confirmation of a scattering of the production processes between richer European countries and those with lower GDP.

Ando (2006 [2]), as well as Kimura, Takahashi and Hayakawa (2007 [25]) stressed how VIIT seems to be of greater significance in East Asian production networks rather than between Western Europe and CEECs. Actually, this might be the case of trade involving Western European countries only. Conversely, trade relationships between most western European countries and some transition countries are expressed by significant values of VIIT, emerging not only from a quality ladder explanation, but also from a high volume of back-and-forth transactions.

\section{Fragmentation: So What?}

The disintegration of production process emerges with the rise of marginal costs that a growing firm faces. If service links to connect scattered production blocks are characterised by increasing returns to scale, firms may take advantage from fragmenting their production processes into different locations. The choice of a national or a foreign place, where to carry out operations, depends of course on a wide variety of elements, the most important of which is probably the local availability of the factor that is used more intensively in that particular production block.

The presence of economies of scale in transport costs is crucial to determine whether firms fragment or not. Provided that manufactures always present economies of scale, transport costs may present either decreasing returns to scale (iceberg type) or increasing returns to scale. In the first case, firms will gain from integrating, in the second case firms will gain from fragmenting. When economies of scale characterise both manufactures and service links, nothing can be said in principle before assessing the relative importance of the two.

Fragmentation may take place either domestically or internationally, and may occur either within the boundaries of a firm or between independent firms.

In Section 2.4 we provided a taxonomy of service link costs. We isolated four categories related to trade, investment, communication and coordination costs, and, to a certain extent, agglomeration, which could be considered as a service link, but also a source of location advantage. The costs of service links increase with the extent of internationalisation and with arm's length transactions. In both these cases there is not only room for outsourcing and subcontracting relationships, but there are also chances for more complex linkages leading to agglomeration. In the American and Japanese case we discussed how firms tend to connect horizontally, by operating in the same industry, and by supplying goods to companies in a vast array of different industries. Conversely, the European model is characterised - in general - by a higher agglomeration of consecutive phases of production and weaker horizontal connections among similar sub-suppliers. In this case, firms often belong to industrial districts, where they can benefit from external economies of scale as a group but suffer from diseconomies of scale individually, due to their small size. This lead companies to create vertically "integrated system of production" to cope with fierce cost competition, especially from East Asia.

It is perhaps ironic that a somewhat opposite pattern of fragmentation affects MNEs in USA and Japan and SMEs in Europe.

Evidence on fragmentation, from the European and East Asian experience shows that the disintegration of production has taken place in both regions with increasing intensity during the last decade, even though with different patterns. Indeed, there seems to be a prevalence of intra-firm fragmentation when Western European firms delocalise in CEECs, whereas the Far East case appears more complex. In East Asia, in fact, a thick web of sub-regional trade flows and inter-firm linkages does appear as stunning, thanks to allegedly lower service link costs in Asia.

Taking into account the relationship between fragmentation and IIT we decided to distinguish between VIIT (when cross-border transactions leave the intermediate goods in the same 
commodity category) and one-way trade when the commodity category changes (within the same industry). Unfortunately, we did not record any contribution on HIIT and fragmentation, but we suppose that this combination can actually emerge when a previously integrated MNE breaks up. In this case different varieties of the same good might be traded internationally to satisfy the consumers' love of variety.

So far for fragmentation itself. We will briefly conclude this paper by providing some very preliminary hints to connect fragmentation with the scholarship on Global Value Chain and on Global Production-Distribution Networks.

\section{Paths for Future Research: Fragmentation, Global Value Chains and Global Production Networks}

At a first glance, value chains and fragmentation may seem extremely different, but at a closer look, one can notice that they are two sides of the same coin. Fragmentation, in the first place, is the mere consequence of the division of a previously integrated MNE, but, in the second place is also a tool to interpret how "local production systems", made up of SMEs, behave internationally.

Global value chains do not care only about MNEs, as they widely refer to "a sequence of related and interdependent value added activities that can be performed by numerous enterprises located in various locations worldwide" (Memedovic, 2008, p. 5 [33]). Such a clear picture do include SMEs, clusters and industrial districts, and it can also be expanded to include regions.

Fragmentation, as we know, may take place within or outside the boundaries of the firm, and in the latter case, we stressed that there is room for agglomeration among independent agents, which may take different forms as provided in both Figures 5 and 7.

Yet, as fragmentation lies in the core of economics, it seems to be partly inadequate to understand, by itself, what happens when looking at firms' dynamics, and, specifically, at inter-firm relations. Conversely, the Global Value Chain and the Global Production Network approaches seem instead appropriate to analyse a selected industry and a selected flagship firm with its local suppliers, respectively.

Recent preliminary research on this path is provided by Kimura (2008, [22]) who highlighted how the in-fashion "new" "new" international trade models of heterogeneous firms do not account for the sophisticated inter-firm relationships recently recorded in East Asia in the machinery industry. The well-known bi-dimensional fragmentation framework is thus slightly enriched to introduce four layers in terms of gate-to-gate lead time and frequency of delivery, namely a local, a sub-regional, a regional and a world layer.

Notwithstanding, the contribution does not seem to bring such a novelty in the field, as it argues that the heterogeneity in inter-firm relations is mainly explained by the transaction cost approach, which is something pertaining to conventional wisdom. 


\section{References}

[1] J. Anderson And E. VAn Wincoop, "Trade Costs", Journal of Economic Literature, 42 (1994), pp. 691-751.

[2] M. Ando, "Fragmentation and Vertical Intra-Industry Trade in East Asia", The North American Journal of Economics and Finance, 17 (2006), pp. 257-281.

[3] M. Ando And F. Kimura, Fragmentation in East Asia: Further Evidence. mimeo, May 2006 .

[4] - Corporate Strategies in the Age of Regional Integration, Edward Elgar, Cheltheham, UK, April 2007, ch. "Fragmentation in Europe and East Asia: Evidences from International Trade and FDI data".

[5] W. Antweiler and D. Trefler, Increasing Returns and All That: A View from Trade. University of British Columbia and University of Toronto, 1997.

[6] S. ARndt, "Globalization and Trade", The World Economy, 20 (1997), pp. 695-707.

[7] P. Athukorala And N. Yamashita, "Production Fragmentation and Trade Integration: East Asia in a Global Context", North American Journal of Economics and Finance, 17 (2006), pp. 233-256.

[8] S. Baldone, F. Sdogati, And L. Tajoli, "Patterns and Determinants of International Fragmentation of Production: Evidence from Outward Processing Trade Between the EU and Central Eastern European Countries", Weltwirtschaftliches Archiv/Review of World Economics, 137 (2001), pp. 80-104.

[9] _ "Moving to Central Eastern Europe: Fragmentation of Production and Competitiveness of the European Textile and Apparel Industry", Rivista di Politica Economica, 92 (2002).

[10] J. Bhagwati and V. Deheja, "Freer Trade and Wages of the Unskilled - Is Marx Striking Again?", in Trade and Wages: Leveling Wages Down?, J. Bhagwati and M. Kosters, eds., The American Enterprise Institute, Washington DC, 1994.

[11] G. Corò, M. Volpe, And S. Bonaldo, "Local Production Systems in Italy between Fragmentation and International Integration", in Economia Internazionale e Sviluppo, Investimenti Diretti Esteri, Commercio Internazionale e Competitività, Università degli Studi di Urbino, Italy, May, 27-28 2005, Gruppo CNR su Economia Internazionale e Sviluppo, Investimenti Diretti Esteri, Commercio Internazionale e Competitività.

[12] A. Dixit And V. Norman, Theory of International Trade, Cambridge University Press, Cambridge, UK, 1980.

[13] W. EтhiER, "The Multinational Firm", The Quarterly Journal of Economics, 101 (1986), pp. 805-833.

[14] R. Feenstra, "Integration of Trade and Disintegration of Production in the Global Economy", Journal of Economic Perspectives, 12 (1998), pp. 31-50.

[15] G. Gereffi, J. Humphrey, and T. Sturgeon, "The Governance of Global Value Chains", Review of International Political Economy, 12 (2005), pp. 78-104.

[16] D. Hummels, D. Rapoport, AND K.-M. Yi, "Globalization and the Changing Nature of World Trade”, December 1997. 
[17] R. Jones And H. Kierzkowski, "The Role of Services in Production and International Trade: A Theoretical Framework", in The Political Economy of International Trade. Festschrift in Honour of Robert Baldwin, R. Jones and A. Krueger, eds., Basil Blackwell, Oxford, 1990, pp. 31-48.

[18] —_, "International Trade and Agglomeration: An Alternative Framework", in Growth, Trade and Economic Institutions, T. Palokangas, B. Jensen, D. Bös, G. Corneo, R. Hjerppe, and J. Honkatukia, eds., Springer Verlag, Wien and New York, 2005.

[19] R. Jones, H. Kierzkowski, And G. Leonard, "Fragmentation and Intra-Industry Trade", in Frontiers of Research on Intra-Industry Trade, P. Lloyd and H.-H. Lee, eds., MacMillan, London, 2002.

[20] R. Jones, H. Kierzkowski, And C. Lurong, "What Does Evidence Tell Us About Fragmentation and Outsourcing", International Review of Economics and Finance, 14 (2005), pp. 305-316.

[21] B. Kaminski And F. NG, "Trade and Production Fragmentation. Central European Economies in European Union Networks of Production and Marketing", World Bank (Trade, Development Research Group) Policy Research Working Paper No. 2611, (2001).

[22] F. KimurA, Vertical Specialization and Economic Integration in East Asia, IDE-JETRO, 2008, ch. "Corporate Activities and the Spatial Structure of Production and Distribution Networks in East Asia", pp. 29-44.

[23] F. Kimura and M. Ando, "Two Dimensional Fragmentation in East Asia: Conceptual Framework and Empirics", International Review of Economics and Finance, 14 (2005).

[24] F. Kimura And Y. TAKahashi, International Trade with FDI and Fragmentation: the Gravity Model Approach. Hitotsubashi Conference on International Trade and FDI 2004, October 2004.

[25] F. Kimura, Y. Takahashi, and K. Hayakawa, "Fragmentation and Parts and Components Trade: Comparison between East Asia and Europe", North American Journal of Economics and Finance, 18 (2007), pp. 23-40.

[26] P. Krugman, "Does Third World Growth Hurt First World Prosperity", Harvard Business Review, 72 (1996).

[27] E. LeAmer, In Search of Stolper-Samuelson Effects on U.S. Wages, NBER Working Paper No. 5427, (1996).

[28] J. Markusen, "Multinational Firms, Location and Trade", The World Economy, 21 (1988), pp. $733-756$.

[29] — "The Boundaries of Multinational Enterprises and the Theory of International Trade", Journal of Economic Perspectives, 9 (1995), pp. 169-189.

[30] J. Markusen and K. Maskus, "A Unified Approach to Intra-Industry Trade and Foreign Direct Investment", in Frontiers of Research on Intra-Industry Trade, P. Lloyd and H.-H. Lee, eds., MacMillan, London, 2002.

[31] J. Markusen and A. Venables, "Multinational Firms and the New Trade Theory", Journal of International Economics, 46 (1998), pp. 183-203.

[32] — - "The Theory of Endowment, Intra-Industry and Multinational Trade", Journal of International Economics, 52 (2000), pp. 209-234. 
[33] O. Memedovic, Globalization, Value Chain Fragmentation and Competitiveness, UNIDO Research and Statistics Branch, April 2008.

[34] F. Ng And A. Yeats, Major Trade Trends in Asia - What Are the Implications for Regional Cooperation and Growth?, World Bank Policy Research Working Paper No. 3084, (2003). 